\title{
COSMOGENIC ARCHITECTURE: A STUDY OF YOKA SARA'S DESIGN APPROACH ON ANTONIO BLANCO'S HOTEL
}

\author{
Dea Aulia Widyaevan \\ Interior Design Programme, Telkom Creative of Indutries School, Bandung, INDONESIA \\ Email: widyaevean@gmail.com
}

\begin{abstract}
The Antonio Blanco's hotel design by Balinese base architect Yoka Sara been design to represent the extension of Antonio Blanco's museum in Ubud Bali. Although this design only achieves in a preliminary stage, the design approach in which Yoka Sara offer to interpret the style of Balinese contemporary, reflect the idea of Cosmogenic Architecture by Charles Jencks. In his book "Architecture of The Jumping Universe" Jencks stated about how in the postmodern era, the architect should have the freedom to use architecture as a language. The nature of architecture has been identified with a definition of the universe through contemporary sciences. This paper tries to reveal the cosmogenic value in Antonio Blanco's hotel approach by analogizing the architectural vocabulary into the linguistic system as Jencks mention in his book "The Language of Postmodern Architecture". The issue of genius loci concept of cosmos also discusses to be coherent with the idea of cosmos in contemporary science. In related to architecture design, and a new way to re-define cosmos in contemporary Balinese architecture.
\end{abstract}

Keywords: Space translation; Yoka Sara; cosmogenic architecture; postmodern architecture; genius loci; a language of architecture.

\section{INTRODUCTION}

We live in a curious time today of the iconic building when we have an iconic building without any understanding of iconology. What should building look like? In what style should we build? What image should it convey? How should public relate to it? Those are a question which reflects crisis in architecture because in this era, the expensive building cannot just disappear and there is a real crisis when society, the client, and architect are more or less confused as to the public meaning and it is contested politically, socially, economically. Responds to that issue, the architecture should have a subject matter.

The subject matter came in a form of style. Charles Jencks thinks that style is a relevant as a visual code to convey metaphor that addresses the issues of our time. In another hand, style is making intentional choices about how buildings are arranged, to move their experience away from the present drive to similarity and recognition to open up the possibility for new types of actions. Architect skeptical building that conveys meaning is that architecture is legible and that the task of an architect is to design a building that people can read just as they do with language or literature. Reading the parts of building relative to the uses intended for the building. Jenks speaks of the use intended of people reading associations external to a piece of architecture as iconology, not ordinary user which lack shared image memories that Jenks proposed an ultimate source of shared meaning today.
Regarding meaning in architecture, many postmodern theorists offer an insight into whats worth becoming a basis of meanings in architecture today. As one of the postmodern theorist, Charles Jenks offers an idea of Cosmogenic Architecture. He explains the idea of evolution on how architecture mimicking universe in contemporary area. Since Vitruvius, the idea of architecture as universe representational has evolved by the time a science invention making sense of the universe. However, $\mathrm{He}$ differentiates between cosmic architecture and cosmogenic architecture which distinguish static cosmology (cosmic) in vernacular view and dynamic and emergent cosmos creation (cosmo-genic) in contemporary views. This concept of cosmo-genic came from a word of cosmos-genesis, which means a procreation of a universe in continuous ways (generative) close to contemporary science such fractals, chaos theory and relativity which attempt to explain the universe in more dynamic, inter-related and sequential ways. This view also supported by Fritjof Capra in his book 'The Tao of physics' He discusses the similarity of contemporary science worldview (relativity, quantum theory etc) to Hinduism, Buddhism and Zen.)

According to Capra, the difference between a traditional culture of the East and contemporary Western science is in the process of revealing the knowledge, not in the result of knowledge. In contemporary Western sciences, they look for the material worlds using scientific methods, While 
Eastern mysticism looks inwards to the mind, meditation and another form of introspection, which both show the aspect of dynamic, cosmogenic universe. According to Jenks, cosmogenic architecture is a result of 'form following worldview' where 'another aesthetic is growing out of this new worldview: an aesthetic language of building and design should close to nature, of twists and folds and undulations; of crystalizing forms and fractured planes" p. 9). Therefore, since the world-view of Hunidushm/Balinese and the new paradigm are shown to be similar by Capra, so should their representation in architecture.

In Indonesia, this issue of - architecture meanings - became very contextual because the question about contemporary architecture in Indonesia cannot be detached from the origin or vernacular style. Indonesia has rich local content which reflects in each if its architecture. Architecture is seen not only as 'functional' building but has second layer meaning which philosophy, a way of life, religion and everything that important in spirituality lies. However, the development of current contemporary architecture in Indonesia has become alarming when most of the architect, client even the public became skeptical about meanings. The building exists only for the meaning of capital reflections, nonetheless by the value of culture or identity preservation.

This paper tries to answer the question of how the contemporary Balinese articulate by Yoka Sara in term of cosmogenic value? The methodology to analyze lies on how theoretical frameworks from Jenks point of view are analyzed to create a dialogue to the Yoka Sara's villa design application by using semantics ways. The use of semantics approach has been using to link the intangible intention which needs a bridge of metaphors to transferred to content into architectural elements. From the analysis, the paper tries to show the process of translating design, with an interdisciplinary approach of ideation to expressing cosmogenic meaning in forms and space.

\section{THEORITICAL FRAMEWORKS}

\section{Cosmogenic Architecture}

On Charles Jencks book " The Architecture of a Jumping Universe", He discusses the implication of new paradigm based on contemporary science and its consequence for architecture. He mentions that architecture experiences a spiritual crisis and the loss of shared metaphysics. He believes that it is a task of architects to take responsibility for this spiritual crisis, whereas it is an extremely difficult task in this global culture where there is no shared value system. In his book, He offers a paradigm of Cosmogenic Architecture. Cosmogenic came from the term of cosmosgenesis which refers to the nature of the universe which single, unfolding, creative for striving selforganization. This paradigm, tells us a new story of the universe - a new genesis. This paradigm offers an insight of transformation in architecture based on science complexity: fractals, nonlinear dynamics, selforganizing systems and the new cosmology. As a result, the significant understanding of cosmogenic architecture sees as an adaptation of 'new cosmos' on architecture.

However, He also differentiates between cosmic architecture and cosmogenic architecture which distinguish static cosmology (cosmic) and dynamic and emergent cosmos creation. " Architecture has always had some cosmic dimension in traditional culture. In India, Egypt, Greece, Japan and in the West throughout Renaissance architects inscribed he cosmos in the buildings, oriented their structure to the propitious points of the universe and represents it in details. Today, architecture must do these things as well as go beyond this to our contemporary view; that is cosmogenesis “(Jenks, 1995).

To contextualized the paradigm of cosmogenic architecture and the case of Yoka Sara's design, there are several issues that can be highlighted as follows:

1. Building as natural language: Jencks mention various manifestation of cosmogenesis in nature and their architectural representations through contemporary science such as fractals, strange attractors, wave, folds etc.

2. Representing the basic cosmogenic truth- self organizing, juxtaposition. Architecture, therefore, dramatize punctuated equilibrium, the optimism, and tragedy, at the same time it is also known as the concept of paradoxes.

3. Architecture should acknowledge the time and the spirit an era, which roots, local content, a building in particular time, place and constructional relevance need to be developed.

4. It should have double coding with aesthetic and conceptual codes: architecture must adopt a shared symbolism - both the local and universal cosmogenic language.

\section{Translating Architecture in Cosmogenic Terms}

To transfer the idea of cosmogenic follows the previous Charles Jencks book "The Language of Post-Modern Architecture" he mentions about seeing architecture analogous to language. This insight aims to see architecture as a tool of communication as a 
language which consisted of meaning and text. Thus, represent an analogy of space to the form of content, as a word and meanings. However, the methods can be referred to the basic coding of language which inherent semantic quality. This method proof the idea of architecture post-modern which favors pluralism, double coding, historical context, and complexity. (Jenks, 1991). In his regard for semiotic rules, this approach gave a new insight on how architecture can be perceived as a cumulative of signs and sign process as visible languages. Moreover, the similarity of architecture and language can be perceived on how the element of signs being proceeded as Words, Syntax, Metaphors, and Semantics.

Words: Word is the fundamental element of sentences to paraphrase content. On architecture, words analogous to architecture elements, such openings, roof, details construction, wall, floor. Similar to words to meaning, those architectural elements have function (as meanings). The composition of these elements represented invisibly, as a result, it signifies a style, which also closely linked on how the choosing vocabulary of words - element architecture- and methods of arranging words in sentences (architecture elements composition) can convey different expressions of meaning. For example, the use of roof shape -pitched and gable-has a different associated meaning on how we perceive style (as an aesthetic visual language and symbolized meaning within context).

Syntax: In order to create sentences, there is a structural rule on how we compose words. To clarify a plural meaning in term of time, place and event, sentences should be composed by syntax. Likely known as grammar on English. As in architecture, composing whole elements to create a building, requires several logics. Syntax knew as a construction of a word in sentences or architectural elements in the building. Jencks also mention how the pure realm of syntax is actually applicable perceptually when it is integrated to semantic fields.

Metaphor: A style to deliver messages on sentences can be varied on how we create a style of composition. It is like an implicit meaning or pretexts on one sentences. Those pretexts meaning can be delivered in a poetical way by choosing the right metaphors. However, the implicit meaning can be relative to the readers. In space, a physical description of its architectural elements can be implied differently within different backgrounds. It is the relativity of words, which depends on which context the sentences used. So, it means that the same building can indicate different meaning when it read from a specific medium as photos or direct experiences. Overall looks at a building as a $3 \mathrm{~d}$ form can adhere metaphors, but also in the 'situational' design can offer the layering of metaphors in term of moods or emotive experience in space.

Semantics: Semantics defines the term of style. It also rooted on the appropriateness of a particular style. Semantic can be referred as a sign system which language holds. Architecture, therefore, can be understood in direct similarity with language and has a reconceptualize potential in semiotic terms. In architecture, instead of words, it's a visual code. It is as similar to different languages has been spoken and used by a different group of people, in different backgrounds, different architectural codes have been evolving as identical to style or genre. Jencks called this 'semiotic group' which each of it speaks their own architectural language.

In order to analyze this semantic componential, the basic elements of expressions in architecture language shall be defined. The significant principle of language can be understood the relationship between something that designates (the significance) and something that is designated (the significance). In the same way, the word stands for certain meaning, which particular architecture element also stand for a certain architectural meaning: architecture must have a signifying reference. Therefore, Jencks mention that cultural significance and codes recommend on what style are used. The style works in different situations and who designs it (contextualism). The appreciation of architectural lies outside of the forms.

\section{METHODOLOGY}

In this study, literature reviews and field investigations have been used to interpret and analyze the design of Yoka Sara' architectural works to explore the nature and specialty of cosmogenic architecture. Furthermore, this method used to create a dialogue between a cosmogenic idea of Jencks and cosmogenic concept in Balinese space. As a result, a new form of architecture is design by Yoka Sara as a form of expression the new-cosmogenic concept in new terms. The analysis of the design through cosmogenic frameworks consist of three phase:

\section{Data Collecting}

The data collected from the design proposal of each project which related the site analysis, ideation process, and $2 \mathrm{~d}-3 \mathrm{~d}$ sketch.

2. Analysis of architectural element in terms of Cosmogenesis paradigm. In the part of the ideation process, the translation methods can be essentials to create a transformation in both meaning, form and spatial experiences. This analysis contains 2 phases: 
a. A process to analogous term from Language to architecture by classifying the elements of language to architecture vocabulary. This involves how spatial geometry, composition, and location inherent the concept of cosmogenic but articulate in contemporary science which building mimicking the language of nature, inherit a quality of self-organizing, juxtaposition, diversity and complexity of double coding

b. Interpreting meaning in new form architecture as a consequence of double-coding approach in Jencks cosmogenic idea. This involves the description of poetic of space designed which represent universe through the narrative approach in space and how metaphors can be used to evoke the audience in more sensational ways, rather than functionals.

The completion of analyses also requires a supporting fact from the thorough discussion, an interview, then verification from the architect also. All those findings will be analyzed in terms of an approach of meta-language in architecture as a new insight of how traditional value can be transferred in a new medium of architecture.

\section{RESULTS AND DISCUSSION}

\section{Yoka Sara Point of View in Cosmos and Design Approach}

Yoka Sara who born as Balinese perceives that in this contemporary era, the old world religion endangers by the challenges that come from rationality and science. He sees that the things that rule all these generations right now are rationality, everything must make sense, coherent and self-consistent and must relate to science.

In this contemporary era, Bali Hinduism is struggling while as an architect he feels responsible to tackle this spiritual crisis into his medium-architecture. He feels the question through the fundamental Hindhu Balinese concept - Dharma is challenged by the way the world sees the culture which dominated by logic. Dharma definition comes from Sanskrit Dara, means " to hold together" so initial inquiry of Hindhu mind is not making one god of creating one universe but instead try to make sense the world around us. Yoka Sara perceive the nature of reality: What makes reality exist? Galaxy, animal, living things, non-living things, mind, intellect, behind all diversity, there is something that holds together as a unity.
Furthermore, Yoka Sara thinks that the crucial tools in order to get a handle on reality are Words, which perceives as a code. Yoka Sara mention, to find a bridge from the metaphysics point of view which perceives universe through symbolism, He feels the essence of a single word has a potential as a code to grasp anything to understand something. He explained that things that we called a codes decide how we handle or perceives the reality, without any form of codes such number, words/ text, audial-tactical- visual codes, world seems to blur, as an animal kingdom who has no rules of codes in terms of communication, then they are living in blur. While human evolve by a process of refining vocabulary so they have tremendous power to reality. Not only text as words, but number, music, gestures, or all the physics equations in science are the refined form of codes, as the medium to grasp reality in further directions.

Based on his understanding of cosmos, in his Architecture design, He offered multiplicity as a philosophical thinking about how architecture as space, related to the reality that contains the essential, dynamic intermingling on a fluid event of experiences as a narration. That idea of seeing architecture as a process of storytelling has been inspiring by the local culture, whereas in Balinese a narrative culture has become a foundation of its arts. Not mentioning only their ancient legends and literature, all the ceremony or rituals also contain a meaningful symbol which has a reference to a story. As a medium to understand reality more, Narrative space also has an ability to reveals 'Taksu'. Taksu is the belief of spirit or energy that rules certain place which only occurs by maintaining the Balinese philosophy into a specific medium. Therefore, Yoka Sara feels that the implementation of cosmos or Dharma in architecture can be an approach in two ways: Analog architecture like literature, which contains various code and language system such words, syntax, metaphor, and semantics, will express the external world of cosmos in the physical aspect of architecture. Secondly, He sees architecture as space which contains poetic emotions such Harnessing emotion, controlling mood to sequence, nurturing positive ambiance through nature and flows of energy, has become a reflection of Dharma in inner-self.

\section{Design Approach an Analysis on Antonio Blanco's Hotel}

The Antonio Blanco Hotel design as an extension of Antonio Blanco museum. Antonio Blanco was a Spanish painter who sent his lives in Ubud for a long time. His painting mainly taking the theme of 
exotism expressions of Balinese woman. In order to design the hotel, the storyline has been applied to design the space sequences. Once, the form of the hotel masses, following the curve and hillside of contours. The idea is to manifest the expression of
Blanco's painting into a building with the content of Balinese philosophy.

On building a sequential space, Yoka Sara composes a chapter of narration which became a metaphor for the reincarnation process as follows:

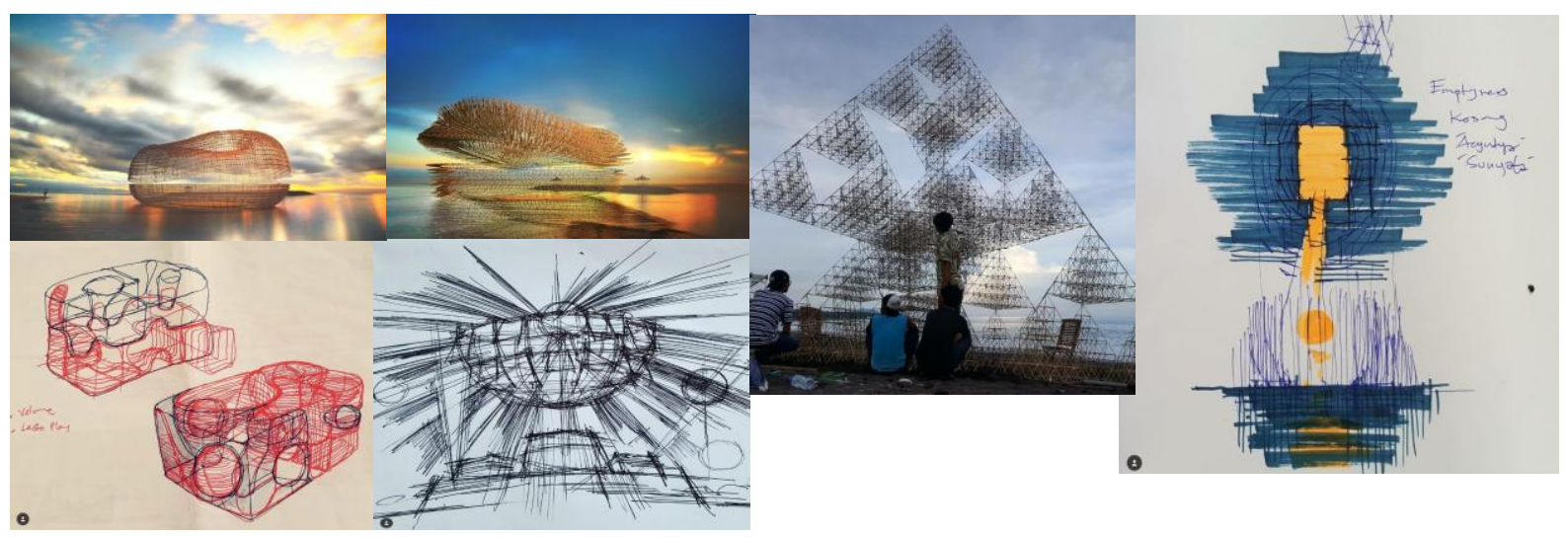

Fig. 1. Yoka Sara's Installation sketch concept, involving the use of fractals geometry and poetic expression of cosmos.

1. Architecture as Semantics
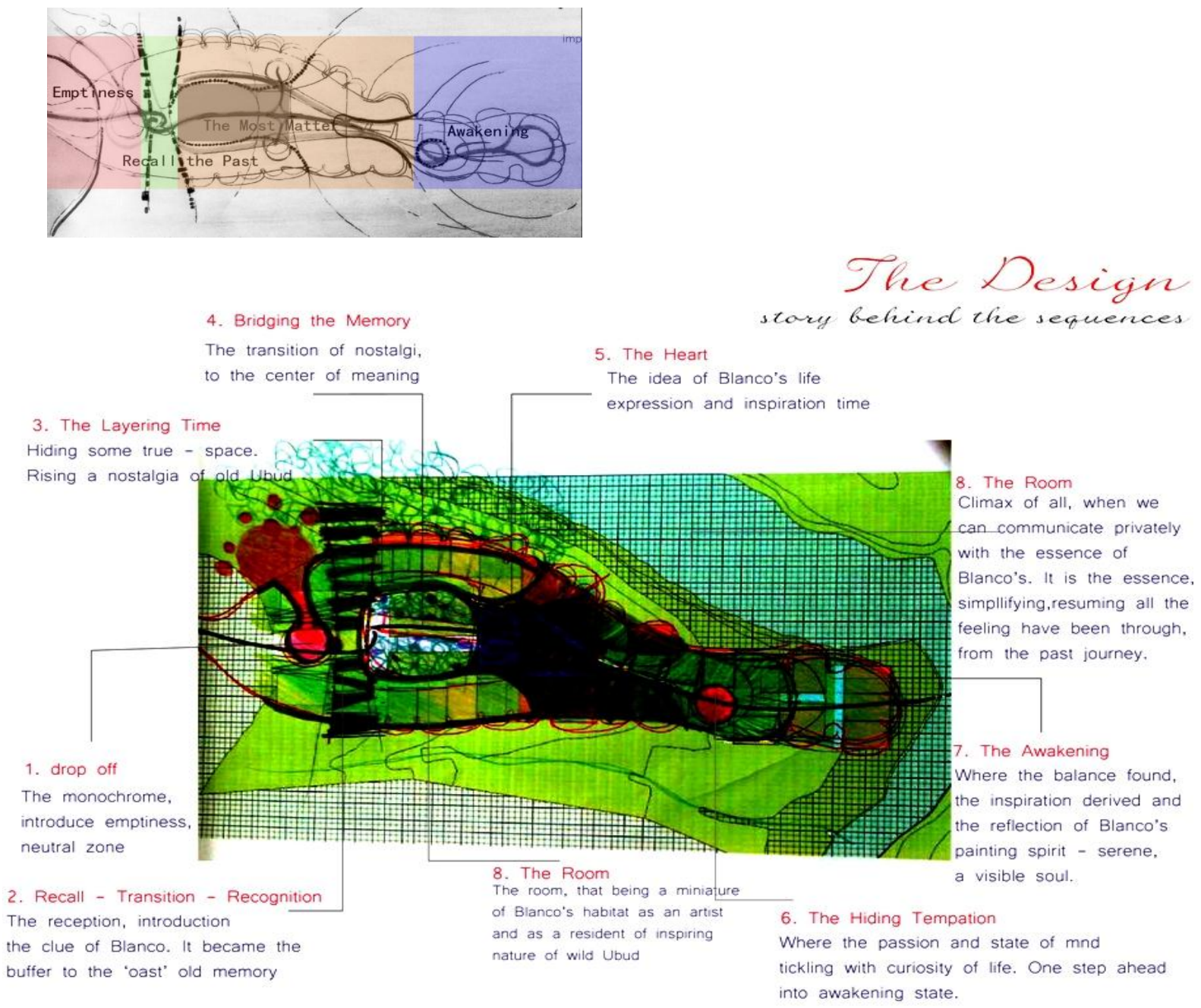

Fig. 2. Antonio Blanco Hotel Space Sequence - Storyline (Source: Antonio Blanco Hotel Design Proposal 2011, sketch by Yoka Sara ed.Iwan Sastrawan) 
Dea A. W.

Meanwhile, to create a spatial story line in his hotels need other imagination to underpin the second meanings. On above diagram, sees that there is a separation of zone/plot: past, present, and future described in the table 1 .

Table 1. A study of semantic approach in Blanco hotel storyline

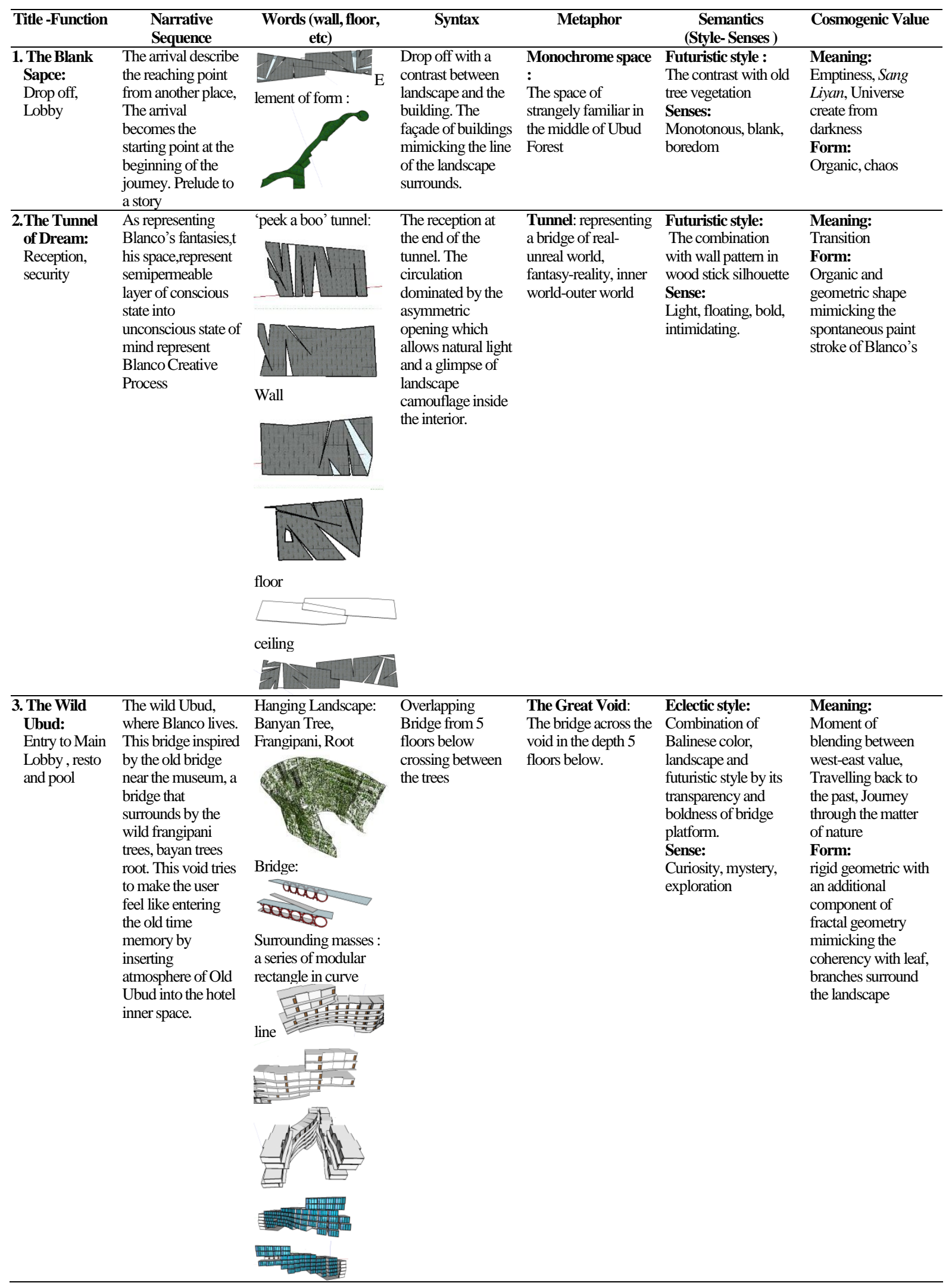






Fig. 3. Antonio Blanco Hotel -Drop Off, The Blank Sapce (Source: Antonio Blanco Hotel Design Proposal 2011, sketch by Yoka Sara ed.Iwan Sastrawan)

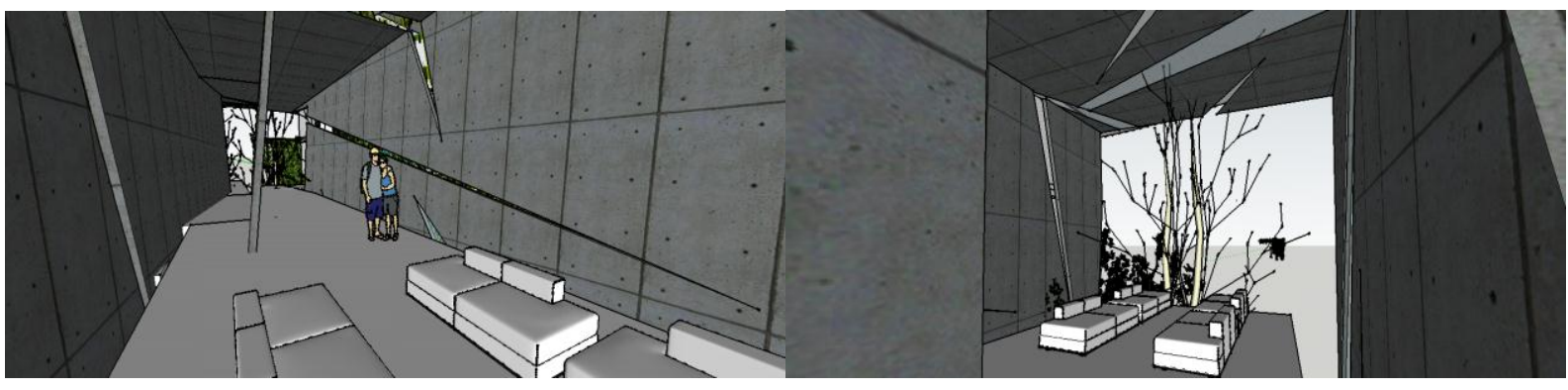

Fig. 4. Antonio Blanco Hotel- Reception, Lounge, The Tunnel of Dream (Source: Antonio Blanco Hotel Design Proposal 2011, sketch by Yoka Sara ed.Iwan Sastrawan) 


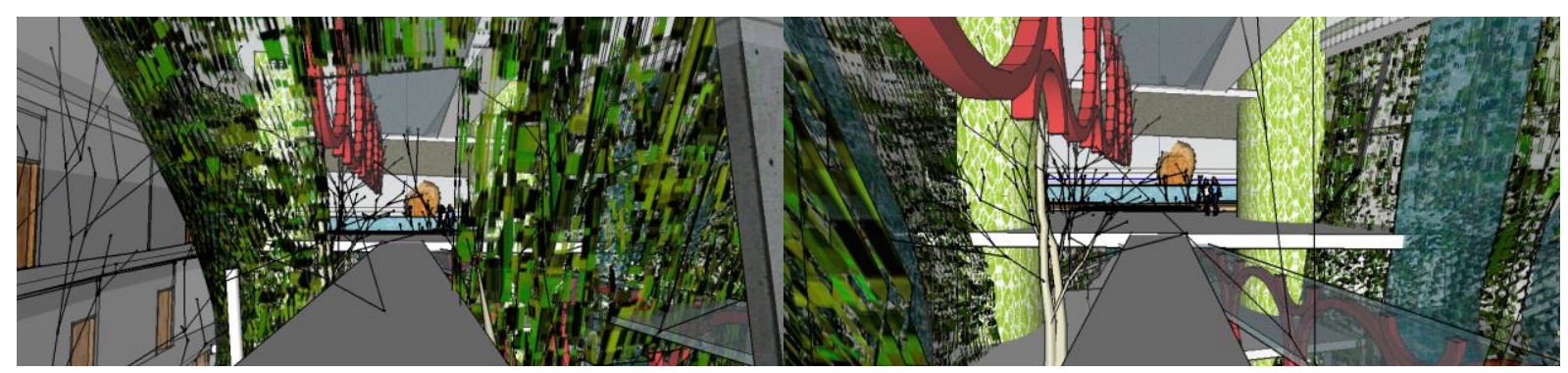

Fig. 5. Antonio Blanco Hotel - Bridge to Lobby, The Wild Ubud (Source: Antonio Blanco Hotel Design Proposal 2011, sketch by Yoka Sara ed.Iwan Sastrawan)

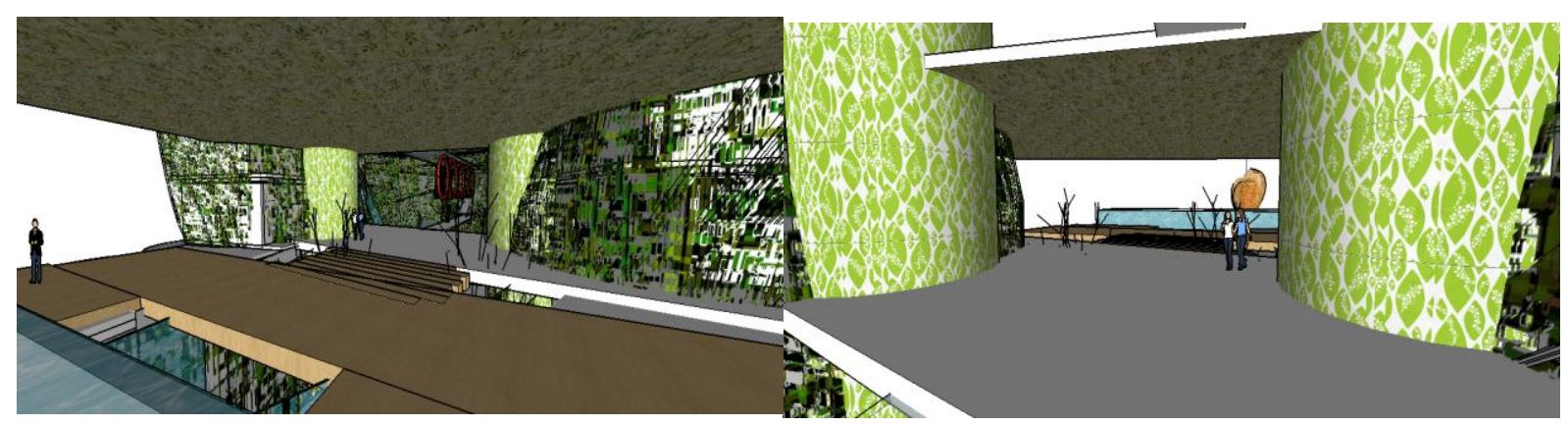

Fig. 6. Antonio Blanco Hotel- Lobby, Restaurant, The Serenade (Source: Antonio Blanco Hotel Design Proposal 2011, sketch by Yoka Sara ed.Iwan Sastrawan)

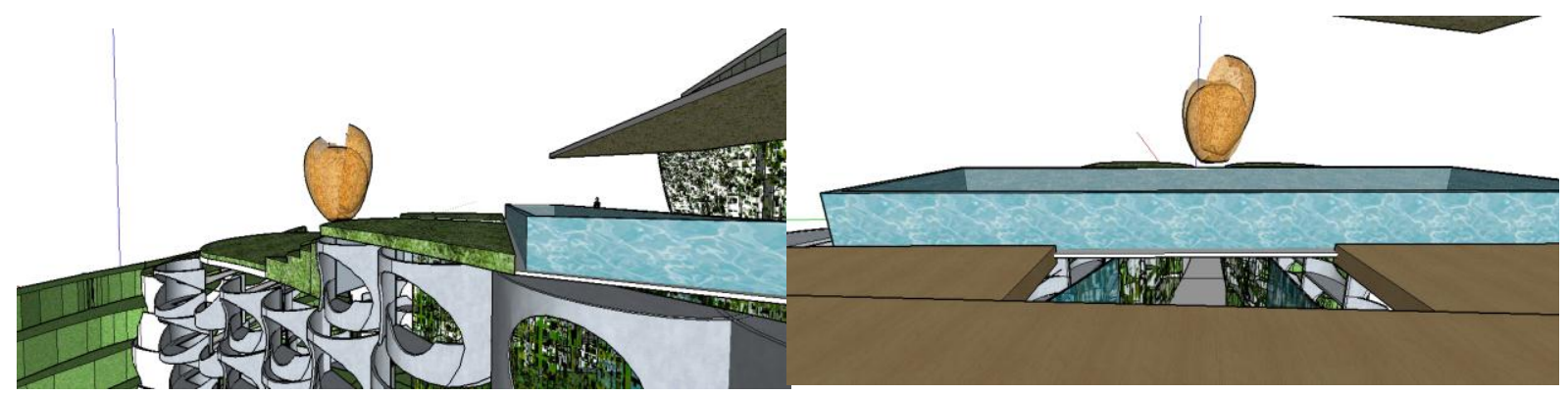

Fig. 7. Antonio Blanco Hotel Space-Infinity Pool, The Poem (Source: Antonio Blanco Hotel Design Proposal 2011, sketch by Yoka Sara ed.Iwan Sastrawan)

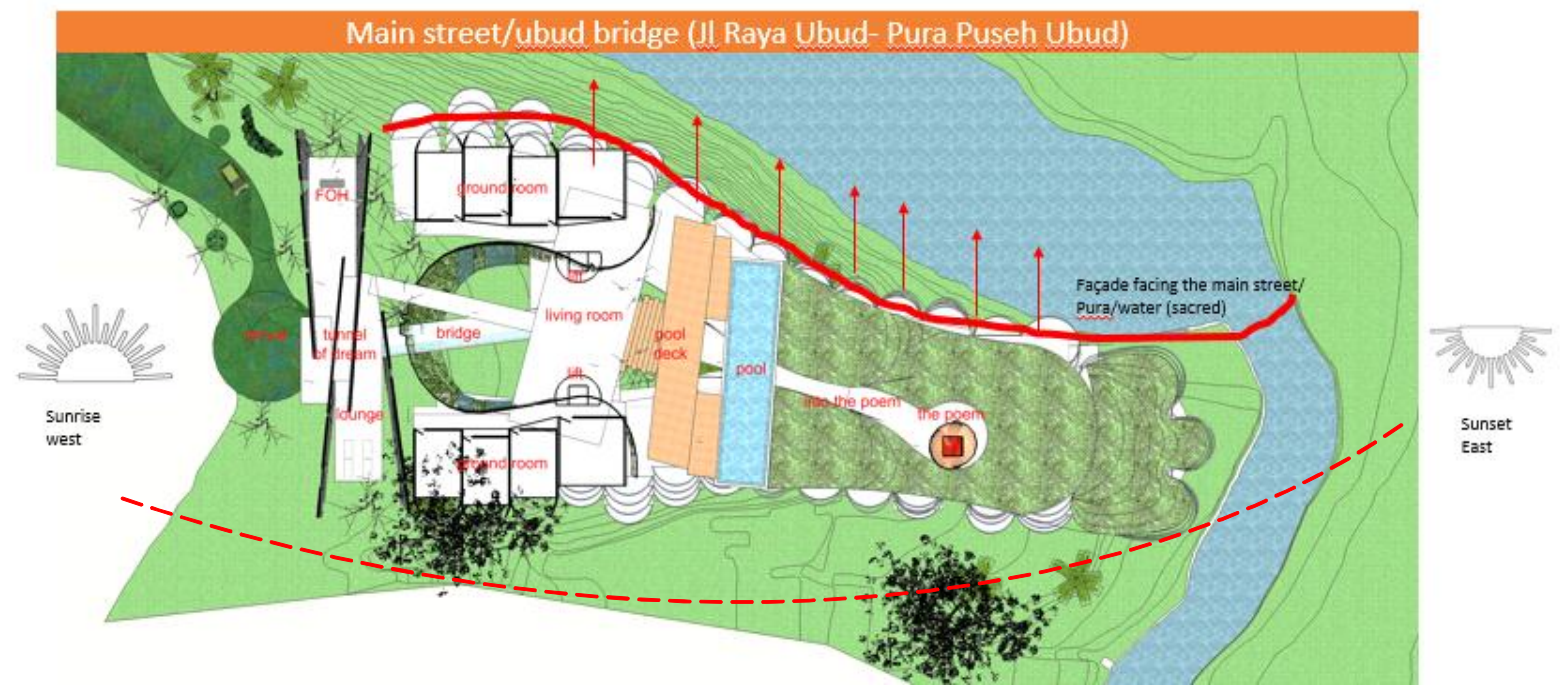

Fig. 8. Hulu Teben concept in mass orientation analysis 
2. The Concept of Universe in Balinese Spatial Arrangement

The concept of Universe in Bali, believe that the essence of the life, real existence is the balance of the paradox. The tension between good-bad, sacredprofane, creates an energy to move the wheel of a life cycle, without the tension in any paradoxical element, the reality won't exist. The binary paradox implemented in a philosophy of Hulu Teben, Rwa Bhineda and Purusa Pradhana

Hulu Teben: Hulu means the orientation of sunrise, mountain and artery street. In Bali, in the whole island has been mapped in an arrangement of
Mount Agung orientation, including the city plan and tree hierarchy. The architecture should follow the orientation of the village or city masterplan which built based an orientation of sun and mountain.

Rwa Bhineda: In spatial arrangement manifest in locating a two paradoxical area at the same such, Nawa Sanga a division of nine squares based on sacred-profane orientation, which includes Pemerajan-Paon ( an opposition of sacred space), Pavillionpaon (an opposition of profane space). Furthermore, the impact of zone separation due to the level of their sacredness and profane creates a hierarchy of space which called Utama-madya-nista, which Utama faced north toward Gunung Agung mountain.

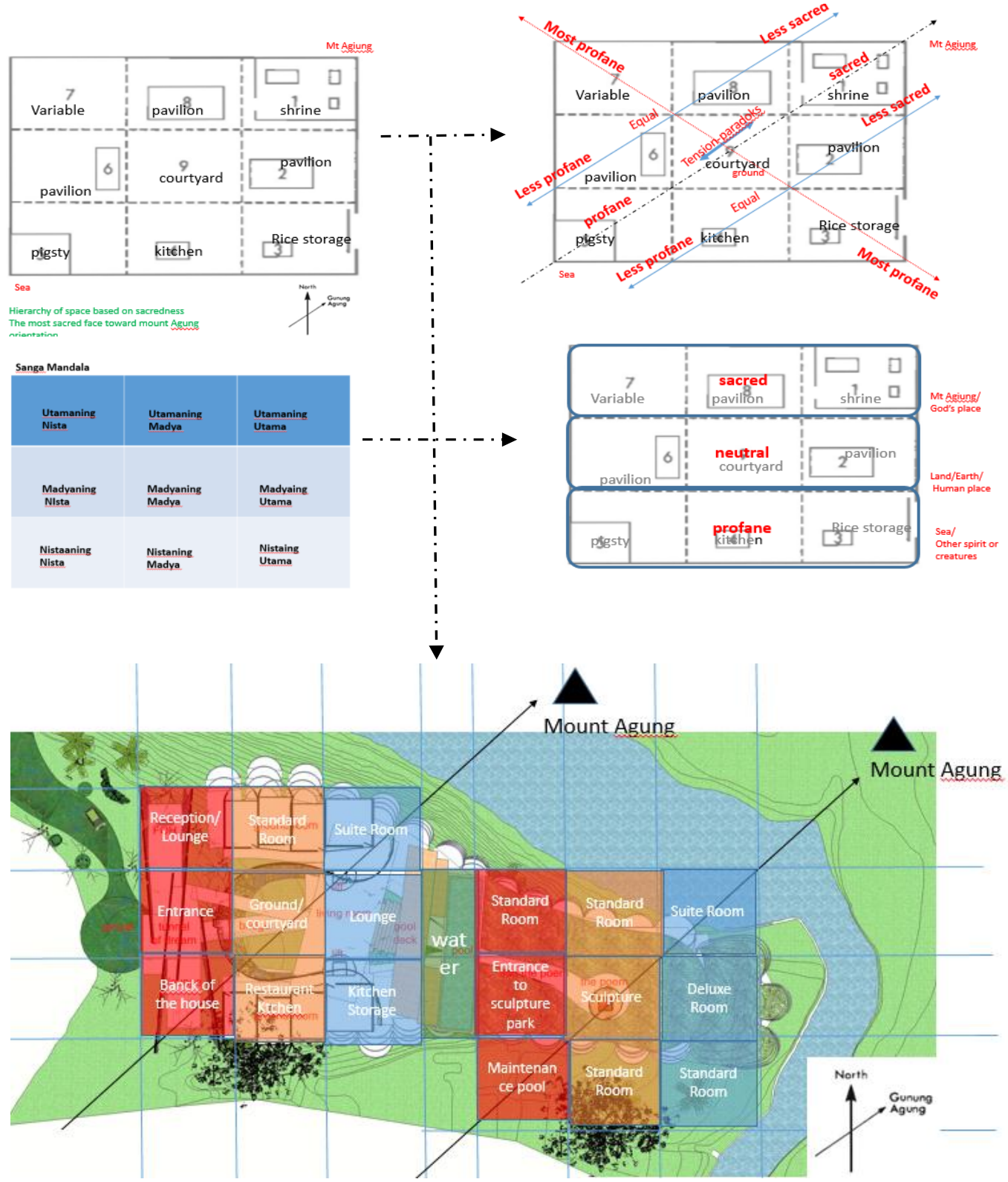

Fig. 9. Rwa Bhineda in Blanco Spatial Arrangement and orientation analysisi 
Purusha Pradana: in Hinduism, Purusha refers to the soul of the universe, the universal spirit present everywhere, in everything and everyone, all the times. Pradana means the creative principle of nature, as the original root of the matter, the Prime Matter. Purusha pradhana in Balinese house known as a spirit, soul of the house, which represents by natah, a void /courtyard between masses. Balinese views a void as the center of everything, such as the creation of universe came from a void. The void sees as the medium which links between sky and earth, Sekala and Niskala. The courtyard, void existence in the center of the house has become a central space for any activity (profane or sacred) act as transitional space in the hierarchy of profane - sacred space.

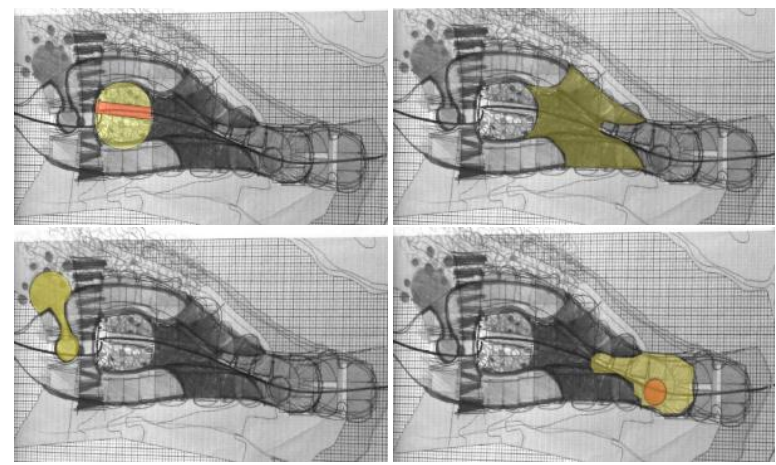

Fig. 10. Natah/void in Blanco's spatial arrangement

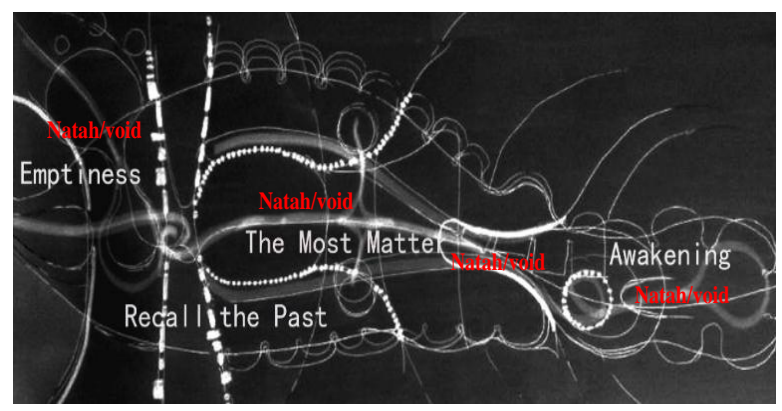

Fig. 11. Natah / void as a transition of story in Blanco's spatial arrangement

The natah/courtyard has become a series of void-space which engage with the storyline idea. Yoka Sara feels that transitional space are very important at defining a moment of pause and completeness of experiences. Toward the prelude to the end of the story, everything enggage with the idea of Rwa Bhined from function zoning, Hulu tebem for mass orientation and Purusha Pradhana for sequence for courtyard/void as mass conector. The whole building not only tell story about Blanco's personality, but also reflect the idea of universe of Balinese.

\section{CONCLUSION}

The exploration of the intangible aspect of architecture has become a starting point to invent a 'language' of architecture nowadays. As in cosmogenic architecture has been showed, the concept of the universe can be articulate both in modern science or in vernacular. However, the dialogue between the science and the cultural value has an interpretative gap which needs to be linked by other medium or design approach in architecture. It is the responsibility of an architect to always find limitless inspiration and creativity to innovate the way architecture can communicate the values. The spirituality, metaphysics aspect of genius loci can be a catalyst to inventing methods.

This kind of exploration could evoke the designer to have a wider aspect of knowledge of design approach which can be adapted to other Indonesia vernacular architecture. The contemporary of architecture in Indonesia need to invent a new articulation of language in design vocabulary, in this case, the semantic approach was used. Cross-discipline fields can be a way to enrich the metaphor in generating form. Spatial experiences can be a pre-text on building new awareness.

On the design approach mention above, there is some resume on how to adapt semantics technique and value:

a) The tools of semantic can be linked./analogue into the idea of form in both exterior-interior architecture, including a use of vegetation or water element.

b) The concept of spatial experience can be approached by narrating a sequence, such interpretingmoods of poetry or substrate of an imaginative story based on context (Blanco-Ubud)

c) The value of cosmogenic (based on Balinese concept) reflect on the spatial arrangement which contains massing orientation, space composition, and the functional zoning.

d) The use of landscape also has a potential to gave dialogue between the given narrative and the existing building which enrich the spatial experience and poetic quality.

So, contemporary architecture can wider their dimension, not stuck only in technicality, function but also able to offer the transcendence experiences. The contemporary architect should see something beyond form. Re-inventing methods of how architecture communicate with the user through spatial value and experience which reflects the spirit of the era. 


\section{ACKNOWLEDGMENT}

The Author would like to acknowledge and be thankful to Mr Yoka Sara who taught a lot about architecture, and how designer should thinks in crossdiscipline ways. Also, special thanks to other creative colleagues who participate on Antonia Blanco's hotel design.

\section{REFERENCES}

Antoniades, A.C. (1990). Poetics of Architecture. New York: Van Nostrandt Reinhold.

Bachelard, G. (1992). Poetics of Space. New york: Beacon Press.

Comaroff, J. \& Ong, K.S. (2013). Horror in Architecture. Singapore: ORO editions.

Fritjof, C. (2010). The Tao of Physics: An Exploration of the Parallels between Modern Physics and Eastern Mysticism Colorado: Shambala publisher.

Foucault, M. (1967). Of Other Spaces, Heterotopias. French journal Architecture/Mouvement/Continuité in October, 1984.
Gelebet, N. (1986). Arstektur Tradisional Bali. Proyek Inventarisasi dan Dokumentasi Kebudayaan Denpasar, Bali.

International, Yoka Sara ltd. (2011). "Blanco Art HotelInitial Idea” Denpasar: Yoka Sara International.

Intervewed with Yoka Sara, Denpasar, Oktober 2013.

Jenks, C. (1995). Architecture of the Jumping Universe. Great Britain: Academy editions.

Jenks, C. (1991). The Language of Post-Modern Architecture. New York: Rizzoli.

Pizzagalli, S. (2009). Essay "Space and Voids" Architecture and Natura Press.

Watkin, D. (1977). Morality and Architecture. Oxfords : Clarendon Press.

Wigley, M. (1995). The Architeture of Deconstrucion: Derrida's Haunt. Massachuchets: The MIT Press.

Von-heine Gelden, R. (1948). Indonesian Art. New york: Antopodea Books, Maps and Prints, ABAA.

Vidler, A. (2002). Warped Space. Massachucets: MIT Press. 